\title{
MELD SCORE EXCEPTION OVEREMPHASIZES THE BENEFITS TO HEPATOCELLULAR CARCINOMA PATIENTS IN TRANSPLANT. A PROPOSAL TO IMPROVE THE RULES
}

\author{
Pontuação especial do MELD beneficia exageradamente pacientes com \\ carcinoma hepatocelular para o transplante. Uma proposta para melhorar as regras
}

Agnaldo Soares Lima, Nathália Nunes Godinho Lopes, Bárbara Buitrago Pereira, Leandro Ricardo Navarro Amado

\begin{abstract}
Purpose: In Model for End-stage Liver Disease (MELD)-based allocation systems patients with cancer and some other diseases are assigned a special score. The goal of this study was to assess the fairness of organ distribution by the MELD system among different groups of diseases. Methods: Retrospective study with adult patients between 2009 and 2013. Demographics and MELD scores were compared with the incidence of transplant or death, patient origin and disease groups. Results: 260 selected patients were submitted to transplant or died before the transplant. Their median age was 54.9 years (12.1 -73.9 years); $70.4 \%$ were men; $63.3 \%$ had chronic liver diseases (alcoholic cirrhosis $33.1 \%$, C-virus cirrhosis $24.2 \%$ ). Exception score was assigned to $26.5 \%$ of listed patients. These patients received $31 \%$ of transplanted organs and had lower pre-transplant mortality or dropout (14.2 times less) rates than the other patients $(p<0.001)$. Receiving exception points resulted in a higher likelihood of being transplanted. Conclusion: The authors propose the use of a regional variable score for transplantation in special situations, which should be based on the median MELD score of the latest transplants for chronic liver diseases, to refrain from harming patients who have access to transplant according to the calculated MELD score.
\end{abstract}

Descritores: Transplantation; Equity in the Resource Allocation; Carcinoma, Hepatocellular.

Instituição:

Transplantation Division, Alfa Institute of Gastroenterology, Hospital das Clínicas da UFMG - Belo Horizonte/BH - Brazil

Correspondência:

Prof. Agnaldo Soares Lima, M.D., Ph.D.,.

Av. Alfredo Balena, 189 / 1405 - CEP 30130-100 - Belo Horizonte/ MG, Brazil.

Tel.: +(55) $313274-6852$

E-mail: agnaldo@gold.com.br

Recebido em: 01/02/2017

Aceito em: 01/03/2017

\section{INTRODUCTION}

Relative organ scarcity is the main reason for mortality on waiting lists for liver transplants. Most countries have a real deficit between the demand for a liver and the availability of grafts. This difference is variable and inversely related to local organ procurement capabilities. One solution to this scarcity problem is to prioritize severely ill patients - in an attempt to reduce the death rate before transplantation. In 2001, a new model based on liver disease severity was introduced to guide the allocation of grafts. Known as MELD, short for: Model for End-stage Liver Disease, this model was quickly adopted by many countries and adapted to their 
different local needs. The MELD score stemmed from a logistic regression analysis with laboratory data from liver disease patients, in whom the rate of bilirubin, creatinine and the international normalized ratio (INR) were associated with a probability of death in 3 months. However, patients with hepatocellular carcinoma (HCC) in cirrhotic livers are not always properly assessed by changes in bilirubin, creatinine and INR, and their cancer is more severe than their baseline liver diseases. Thus, HCC patients were assigned scores to adjust for dropout likelihood because of cancer progression, visà-vis the predicted mortality for cirrhotic patients. In Brazil, the MELD-related severity waiting list and its exceptions were established in July, 2006. Candidates for transplantation with malignant liver tumors (HCC, hepatoblastoma, neuroendocrine tumor metastasis) and benign (hepatic adenomatosis) are assigned 20 points upon enrollment on the list, going to 24 and 29 points if not transplanted after 3 and 6 months of entry in the queue, respectively. This assigned score frame is fixed, without any relationship with calculated MELD of other non-special diseases on the waiting list.

To include cancer patients with a special scoring system has an impact on the transplantation possibility of other patients, whose severity is measured by the calculated MELD. This study is designed to check for parity in transplant opportunities for patients with liver tumors when compared to patients with other diseases, considering the waiting list in a specific state in Brazil.

\section{PATIENTS AND METHODS}

This is a retrospective study of patients referred to the Liver Transplant Ward of the Federal University of Minas Gerais Medical School Hospital (HC-UFMG) who were accepted as candidates for liver transplant, from January 2009 to October 2013. We obtained the information from the electronic files (Zeus system) of the Transplant Group from the Alfa Institute of Gastroenterology, of a prospective database maintained for all the patients referred to the institute for liver transplantation. Data collection was performed in October 2014. The study was carried out after approval from the Ethics and Research Committee of the Federal University of Minas Gerais (COEP-UFMG) - protocol \#533,724. We excluded patients with age under 12 years, cases of fulminant hepatitis and those with incomplete data that prevented proper analysis. In cases of patients submitted to re-transplantation, we used only the results from the first procedure.

The patients were enrolled on the transplant list after being submitted to standard preoperative assessment. The National Transplant System (SNT) manages the waiting list, and organ allocation is carried out according to the severity of candidates' illnesses, as measured by the MELD score. The MELD score is calculated considering the levels of total bilirubin, creatinine and INR. A special score is used for the allocation of organs to patients with liver tumors, using pre-established values without calculating the score. These values were 20 points upon enrollment, 24 and 29 points after 3 and 6 months without transplantation, respectively.

Patients were characterized by gender, age, origin, indication for transplantation, time elapsed between the first consultation and the waiting list enrollment, time between list enrollment and the final event, final event type, total bilirubin, creatinine, INR, sodium, MELD and MELD sodium (MELD-Na) values upon the first visit (initial) and the last value before the final event.

Patient origin was categorized according to the planning regions of the state of Minas Gerais.. ${ }^{1}$ The diseases that made up transplant indications were grouped as follows: A - chronic liver cholestatic diseases (primary sclerosing cholangitis, primary biliary cirrhosis, cholangiopathy); B - chronic hepatocellular diseases (C and $B$ post-viral cirrhosis; alcoholic cirrhosis; cryptogenic cirrhosis, and post NASH); C- metabolic liver diseases (hemochromatosis, Wilson's disease) and D - liver tumors (HCC and others). The final events were categorized as "still on the list", "off the list", "transferred to another service", "clinical improvement", "contraindication to the procedure", "pre-transplant death" and "transplant". Initial total bilirubin, creatinine, INR, sodium, MELD and MELD-Na values were recorded upon patient enrollment on the list, and the final cases at the end of the last visit before the final event. MELD values were calculated according to the Malinchoc formula. ${ }^{2}$ MELD$\mathrm{Na}$ values were calculated according to the formula from Kim et al. for hyponatremic patients with serum sodium concentration equal to or less than $130 \mathrm{mEq} / \mathrm{L} .^{3,4}$

Qualitative variables were analyzed by frequency. Quantitative variables were tested as to their distribution, and the proper parametric and non-parametric tests were applied. Evolutionary analysis of variables was performed by paired $\mathrm{T}$ test. The significance level used for all analyses was $5 \%$. We used the SPSS software (IBM version 20) for the statistical analysis.

\section{RESULTS}

During the study period 301 patients were included on the waiting list for liver transplantation. For comparison purposes, only those whose final status was "transplanted" $(n=226,86.9 \%)$ and "pre-transplant death" $(n=34$, 
$13.1 \%$ ) were considered, from a total of 260 patients. Non-analyzed cases were those still on the waiting list $(n=26)$, those temporarily excluded $(n=5)$, those with clinical improvement precluding transplantation $(n=4)$, those with newly onset disease contraindicating transplantation $(n=4)$, and those transferred to another transplant center $(n=2)$. No tumor patient in this series was excluded from the waiting list for dropout according to the Milan criteria.

The study population was mostly male ( $n=183,70.4 \%)$, with a median age of 54.6 (12.1 to 73.9$)$ years. The patients came mainly from the state of Minas Gerais (n $=240,92.3 \%)$. In the state, 164 patients $(68.3 \%)$ were from the Central region (I) followed by the Zona da Mata (II) (10.4\%); the Midwest (5.8\%) and South Minas Gerais (South of the state), (5.4\%). Other regions had very little participation, less than $3 \%$ each. Patients from other states $(7.7 \%)$ were mainly from the states of Bahia and Sao Paulo. There was no difference ( $p>$ 0.05 ) in the number of patients with a special score among all the cases - when the patient came from the countryside of Minas Gerais (22.4\%) or another state (25.0\%), compared to the patients from the Capital city of the state $(30.9 \%)$. In addition, patient gender was not a factor influencing the likelihood of being transplanted.

When comparing the time lapse between the first patient visit and the waiting list enrollment, the group of "transplanted" patients had a median value of 202.0 days (0-1,285 days) and the group of "pre-transplant mortality" patients had a median value of 123.0 days (21,068 days) with no statistically significant difference $(p>0.05)$. The time between the enrollment on the list and the final event for the "transplanted" group had a median value of 41 days $(0-1,063)$ and for the "pretransplant death" group the median was 29.5 days (1368) $(p=0.10)$. There was no difference between the time intervals of patients with or without a special score (Table 1). When analyzed according to the indication for transplantation groups (A, B, C and D) there was also no difference between the time-interval and the final event.

The group of patients who died before transplantation had higher initial and final MELD and MELD-Na scores than the group of transplanted patients. Among the transplanted patients, those whose allocations were based on a special score, had lower MELD and MELD$\mathrm{Na}$ calculated scores than the others $(p=0.001)$. The group of patients submitted to transplant had lower calculated scores than that of patients who died without transplantation. Among the MELD score components, just creatinine did not follow the severity expression of those patients who died before transplantation. The serum sodium of the deceased patients was lower than those transplanted, except when compared to those who did not have a special score (Table 2).

Table 1 - Length of time to enter waiting list and length of time from waiting list to final event in patients with or without exception points.

\begin{tabular}{|c|c|c|c|c|c|c|c|c|c|c|c|}
\hline \multirow{7}{*}{ 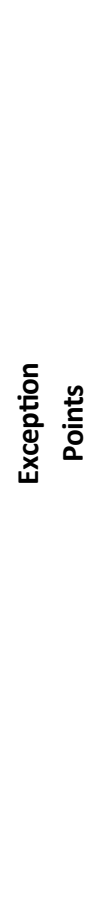 } & & \multicolumn{5}{|c|}{ LOT1 } & \multicolumn{5}{|c|}{ LOT2 } \\
\hline & & \multicolumn{2}{|r|}{ PreOp death * } & \multirow{2}{*}{$\mathbf{p}$} & \multicolumn{2}{|c|}{ Transplantation * } & \multicolumn{2}{|c|}{ PreOp death * } & \multirow{2}{*}{ p } & \multicolumn{2}{|c|}{ Transplantation * } \\
\hline & & $\mathbf{n}$ & Time & & $\mathbf{n}$ & Time & $\mathbf{n}$ & Time & & $\mathbf{n}$ & Time \\
\hline & $\mathbf{N}$ & 33 & 130 (2-1068) days & 0.218 & 158 & $208(0-1167)$ days & 33 & 30 (1-368) days & 0.037 & 158 & $39(0-1063)$ days \\
\hline & $\mathbf{Y}$ & 1 & 64 days & 0.377 & 68 & 175 (0-1285) days & 1 & 16 days & 0.493 & 68 & 46 (1-532) days \\
\hline & & 34 & 123 (2-1068) days & 0.049 & 226 & $202(0-1285)$ days & 34 & $\begin{array}{c}29,5(1-368) \\
\text { days }\end{array}$ & 0.124 & 226 & 41 (0-1063) days \\
\hline & & $\begin{array}{l}\text { LOT1 - } \\
\text { LOT2 - } \\
\text { PreOp } \\
N=N o \\
{ }^{*} p>0.0\end{array}$ & $\begin{array}{l}\text { Median length of time } \\
\text { Median length of time } \\
=\text { pre operative; } \\
Y=\text { Yes; } \\
\text { comparing patients } w\end{array}$ & $\begin{array}{l}n \text { first ap } \\
n \text { waiting }\end{array}$ & $\begin{array}{l}\text { itmer } \\
\text { enro }\end{array}$ & $\begin{array}{l}\text { to waiting list enroll } \\
\text { nent to final event; } \\
\text { points }\end{array}$ & & & & & \\
\hline
\end{tabular}


Agnaldo Soares Lima, Nathália Nunes Godinho Lopes, Bárbara Buitrago Pereira, Leandro Ricardo Navarro Amado

Table 2 - MELD components and initial and final MELD scores for transplanted and non-transplanted group of patients

\begin{tabular}{|c|c|c|c|c|c|c|c|}
\hline & $\begin{array}{c}\text { Values at } \\
\text { Transplantation }\end{array}$ & $p^{1}$ & $\begin{array}{c}\text { Values at Pre-Op } \\
\text { death }\end{array}$ & $p^{2}$ & $\begin{array}{l}\text { Transplanted - } \\
\text { calculated score }\end{array}$ & $p^{3}$ & $\begin{array}{l}\text { Transplanted- } \\
\text { Exception score * }\end{array}$ \\
\hline $\begin{array}{l}\text { Initial Creatinine } \\
\text { (mg/dl) }\end{array}$ & $0.8(0.0-3.7)$ & 0.07 & $1.0(0.0-3.7)$ & 0.18 & $0.81(0.0-3.7)$ & 0.1 & $0.80(0.4-2.1)$ \\
\hline $\begin{array}{c}\text { Initial total } \\
\text { Bilirubin (mg/dl) }\end{array}$ & $2.5(0.3-28.8)$ & $<0.05$ & $4.0(0.6-41.4)$ & 0.005 & $2.81(0.5-28.8)$ & $<0.001$ & $1.67(0.3-12.2)$ \\
\hline Initial INR & $1.6(0.9-4.1)$ & $<0.05$ & $1.9(1.1-9.7)$ & 0.023 & $1.66(1.1-4.1)$ & $<0.001$ & $1.31(0.9-2.5)$ \\
\hline $\begin{array}{c}\text { Initial serum } \\
\text { sodium (mEq/L) }\end{array}$ & $138(111-155)$ & $<0.05$ & $136(128-154)$ & 0.081 & $138(111-155)$ & 0.009 & $139(130-150)$ \\
\hline $\begin{array}{l}\text { Initial MELD } \\
\text { score }\end{array}$ & $16(6-35)$ & $<0.05^{\mathrm{A}}$ & $21(10-50)$ & $0.003^{B}$ & $17(11-35)$ & $<0.001^{c}$ & $12(6-26)$ \\
\hline $\begin{array}{l}\text { Initial MELD } \\
\text { sodium score }\end{array}$ & $16(6.0-36.3)$ & $<0.001^{a}$ & $21(12-50)$ & $0.001^{b}$ & $18(11-36)$ & $<0.001^{c}$ & $12(6-26)$ \\
\hline $\begin{array}{l}\text { Final MELD } \\
\text { score }\end{array}$ & $17(6-51)$ & 0.002 & $25(11-40)$ & 0.011 & $18(9-45)$ & 0.001 & $13(6-51)$ \\
\hline $\begin{array}{l}\text { Final MELD } \\
\text { sodium score }\end{array}$ & $17(6-51)$ & $<0.001$ & $25(12-40)$ & 0.001 & $18(9-45)$ & $<0.001$ & $13(6-51)$ \\
\hline
\end{tabular}

Pre-Op = Pre operative. $A, B, C$ indicate $p<0.05$ comparing initial to final MELD scores in each group. a,b,c indicate $p<0.05$ comparing initial to final MELD sodium scores in each group.

p1 indicates $p$-values in comparing variables from transplanted to pretransplant-dead patients;

p2 indicates $p$-values in comparing variables from pretransplant-dead patients to patients transplanted with calculated MELD score;

p3 indicates $p$-values in comparing variables from patients transplanted with calculated MELD to patients transplanted with MELD exception scores;

${ }^{*}$ indicate values from calculated MELD and MELD-sodium without exception scores; INR - international normalized ratio.

\section{LIVER DISEASE ETIOLOGY AND THE LIKELIHOOD OF TRANSPLANTATION OR DEATH}

As to the indications for liver transplantation, 25 patients $(9.6 \%)$ had chronic cholestatic liver disease (group A); 164 patients $(63.3 \%)$ had chronic hepatocellular disease (group B); 12 patients $(4.6 \%)$ had metabolic disorders (group C) and 59 patients $(22.7 \%)$ had liver tumors - primary or not, malignant or not (group D). Sixty-nine patients were enrolled on the waiting list with a special score (26.5\%), mostly due to benign or malignant tumors ( $n=57 ; 21.9 \%$ ). Other, non-neoplastic indications with special scoring were: type I glycogenosis, oxalosis and amyloidosis.

Preoperative mortality between the patients from groups $A$ and $B$ was higher than the group of patients with cancer ( $p=0.04$ and $p=0.002$, respectively). There was no difference between the preoperative mortality in patients with metabolic diseases and cancer (Table 3).

In all groups of diseases investigated, except the group of metabolic diseases (group C), the patients who died before transplantation were more severely ill upon enrollment on the waiting list than their transplanted counterparts - based on the initial and final MELD-Na values. Comparing the various disease groups, those patients who died in Groups A, B and D, were equally severely ill. Among the transplanted patients, those with cholestatic and hepatocellular diseases (A and B) had similar severity. Also, patients with metabolic disease and those transplanted because of tumors (C and D) had similar initial and final MELD-sodium score. However, when we compared severity using the MELD sodium system among the transplanted patients, those from groups $A$ and $B$ had higher scores than patients in Groups C and D (Table 4).

\section{EXCEPTION POINTS AND LIKELIHOOD OF TRANSPLANTATION OR DEATH}

Patients who were assigned a special score had a 14.20 fold greater likelihood of being transplanted than of dying while on the waiting list (OR 14.20, 95\% Cl: 1.90-105.96, p 0.01). For hepatocellular carcinoma patients, the incidence of dropout according to the Milan criteria was equivalent to death for purposes of analysis of transplant efficiency. Notwithstanding, in this series none of the tumor patients had progression to dropout according to the Milan criteria. The exception points provided a greater likelihood of transplant than the calculated score, as the median value of points assigned to patients with special situations was almost usually higher than the median value of the calculated MELD, concerning the population of this specific waiting list (figure 1). 
Table 3 - Groups of indications for liver transplantation

\begin{tabular}{|c|c|c|c|c|c|c|c|c|c|c|}
\hline $\begin{array}{l}\text { Group of Indications to } \\
\text { liver transplantation }\end{array}$ & \multicolumn{2}{|c|}{ Initial MELD-Na } & \multicolumn{2}{|c|}{ Final MELD-Na } & \multicolumn{3}{|c|}{ Preoperative death } & \multicolumn{3}{|c|}{ Transplant } \\
\hline A & \multicolumn{2}{|c|}{$20.0(7.0-34.0)^{1}$} & \multicolumn{2}{|c|}{$20.5(6.0-38.0)$} & \multicolumn{3}{|c|}{$3(12.0 \%)^{5,6,7}$} & \multicolumn{3}{|c|}{$22(88.0 \%)$} \\
\hline B & \multicolumn{2}{|c|}{$19.0(11.0-50.0)^{2}$} & \multicolumn{2}{|c|}{$19.0(9.0-45.0)$} & \multicolumn{3}{|c|}{$30(18.3 \%)^{8,9}$} & \multicolumn{3}{|c|}{134 (81.7\%) } \\
\hline C & \multicolumn{2}{|c|}{$15.5(6.0-27.0)^{3}$} & \multicolumn{2}{|c|}{$8.5(6.0-24.0)$} & \multicolumn{3}{|c|}{$0(0 \%)^{10}$} & \multicolumn{3}{|c|}{$12(100 \%)$} \\
\hline D & \multicolumn{2}{|c|}{$13.0(6.0-26.7)^{4}$} & \multicolumn{2}{|c|}{$14.0(6.0-51.0)$} & \multicolumn{3}{|c|}{$1(1.7 \%)$} & \multicolumn{3}{|c|}{$58(98.3 \%)$} \\
\hline \multicolumn{3}{|l|}{ Total } & & & \multicolumn{3}{|c|}{34 (13.1\%) } & \multicolumn{3}{|c|}{$226(86.9 \%)$} \\
\hline \multicolumn{11}{|c|}{$\begin{array}{l}1 \text { - } p=0.189 \text { vs Final MELD-NA Group A; } 2-p=0.01 \text { vs Final MELD-Na Group B; } 3-p=0.067 \text { vs Final MELD C; } 4-p=0.12 \text { vs Final MELD-Na D (paired T-test) } \\
\text { Preoperative mortality: } 5-A \text { vs } B-p=0.44 ; 6-A \text { vs } C-p=0.21 ; 7-A \text { vs } D-p=0.04 ; 8-B v s C-p=0.10 ; 9-B \text { vs } D-p=0.002 ; 10-C v s D-p=0.65(C h i-s q u a r e t e s t)\end{array}$} \\
\hline \multicolumn{3}{|c|}{$\begin{array}{l}\text { Table } 4 \text { - In-and extra-group comparison of MELD scores for } \\
\text { transplanted patients and patients dead in waiting list }\end{array}$} & \multicolumn{4}{|c|}{ Preoperative Death } & \multicolumn{4}{|c|}{ Transplant } \\
\hline Groups of indication to li & splantation & Score & $\mathbf{n}$ & Median & $\mathbf{p}$ & $\%$ & $\mathbf{n}$ & Median & $\mathbf{p}$ & $\%$ \\
\hline \multirow{2}{*}{\multicolumn{2}{|c|}{ A-Chronic cholestatic diseases }} & MELD-Na i & \multirow{2}{*}{3} & $\begin{array}{c}27.3^{1,2,3} \\
(25.0-34.0)\end{array}$ & \multirow{2}{*}{0.180} & \multirow{2}{*}{12.0} & \multirow{2}{*}{22} & $\begin{array}{c}19.5^{2,5,7} \\
(7.0-30.0)\end{array}$ & \multirow{2}{*}{0.752} & \multirow{2}{*}{88.0} \\
\hline & & MELD-Na f & & $\begin{array}{c}34.2^{1,2,3} \\
(30.4-38.0)\end{array}$ & & & & $\begin{array}{c}20.0^{2,6} \\
(6.0-30.0)\end{array}$ & & \\
\hline \multirow{2}{*}{\multicolumn{2}{|c|}{ B - Chronic hepatocellular diseases }} & MELD-Na i & & $\begin{array}{c}23.0^{1,4} \\
(12.0-50.0)\end{array}$ & & & & $\begin{array}{c}18.0^{8,9} \\
(11.0-38.0\end{array}$ & & \\
\hline & & MELD-Na f & 30 & $\begin{array}{c}24.0^{1,4} \\
(12.0-40.0)\end{array}$ & 0.021 & (5. & דנז & $\begin{array}{c}18.0^{8,9} \\
(9.0-45.0)\end{array}$ & 0.000 & 01.7 \\
\hline C - Mataholic & & MELD-Na i & 0 & - & & ה 0 & 12 & $\begin{array}{c}15.5^{10} \\
(6.0-27.0)\end{array}$ & 0165 & ה 100 \\
\hline 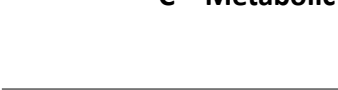 & & MELD-Na f & 年 & - & & 0.0 & 12 & $\begin{array}{c}8.5^{10} \\
(6.0-24.0)\end{array}$ & 0.700 & 100.0 \\
\hline & & MELD-Na i & & $\begin{array}{c}26.0 \\
(26.0-26.0)\end{array}$ & & & & $\begin{array}{c}13.0 \\
(6.0-26.7)\end{array}$ & & \\
\hline o tivetio & & MELD-Na f & & $\begin{array}{c}32.3 \\
(32.3-32.3)\end{array}$ & & A. & & $\begin{array}{c}14.0 \\
(6.0-51.0)\end{array}$ & & \\
\hline
\end{tabular}

MELD-Na $i=$ Initial MELD-sodium; MELD-Na $=$ Final MELD-sodium; 1 - $p<0.05$ Preoperative death vs Transplant; 2 - $p>0.05$ A vs. B; 3 - $p>0.05$ A vs. $D$; 4 - $p>0.05$ B vs. $D ; 5-p>0.05$ A vs. $C ; 6-p=0.06 ; 7-p<0.05$ A vs. $D ; 8-p<0.05$ B vs. $C ; 9-p<0.05 B$ vs $D ; 10-p>0.05 C$ vs $D$.

Figure 1 - MELD score at transplantation for patients with or without exception score, by 6-month periods from January 2009

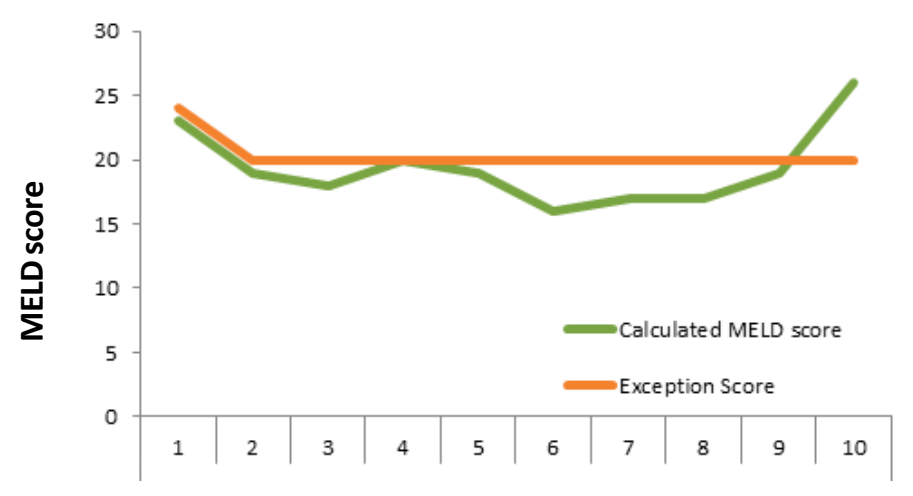

6-Month Period 


\section{DISCUSSION}

MELD-based organ allocation was used in order to identify the severity of patients on the waiting list, aiming at preventing pre-transplant mortality. Patients with cancer and patients with metabolic diseases, whose need for transplantation cannot be measured by the calculated MELD score, are assigned a special score according to the legislation of Brazil and that of other countries. This adjustment enables patients with liver cancer to have a chance of treatment, even with closeto-normal bilirubin, INR and creatinine levels. However, the value of this special score must be calibrated in order to allow similar transplantation possibilities when compared to patients with chronic liver disease. When MELD was originally designed, the special score was equivalent to a $15 \%$ probability of death for the nontumor candidates. The concept of proportionality was ratified at a National Conference on allocation of livers for transplantation in patients with HCC. ${ }^{5}$

We studied 301 patients with liver disease referred to transplant during a period exceeding four years. We selected only those patients who evolved to transplantation or death on the waiting list -260 patients were considered for analysis. The incidence of transplant was $86.9 \%$ in this group. Patient gender or origin did not influence the likelihood of being transplanted; however, in the number of cases treated by region there were less patients coming from the countryside of the state of Minas Gerais, as previously reported in another publication. ${ }^{6}$

Patients who died before being submitted to the transplant were more severely ill with chronic hepatitis, according to the calculated MELD score (with no special score). Although there was a tendency towards less time in performing preoperative tests for these more severely ill patients (123 days vs. 202 days), the effort to take them quickly to the transplant was not enough to prevent their death. On the other hand, individuals with transplant indication with metabolic disease (Group C) or cancer (Group D) had lower calculated MELD severity when compared to those affected by cirrhotic disease (Groups A and B). Nevertheless, the latter had easier access to the transplant - which may be attested by the ratio of patients who died vis-à-vis the transplanted ones $(C$ and $D=1.4 \%$ vs $A$ and $B=$ $17.6 \%)$. This ratio is clearly at odds with the principles of special scoring, which aims to match the dropout or mortality rate with the mortality of candidates listed by the calculated severity score. The low mortality rate in the metabolic diseases group may also be explained by the lack of liver dysfunction, which is common to the nature of these diseases.
Seven out of the $12(58.3 \%)$ patients from group C benefited from the special score they were given because of their amyloidosis (3 cases); type I glycogenosis (3 cases) and oxalosis (1 case), according to the Brazilian legislation on transplants.

The study population, derived from a Brazilian public university hospital, faces difficulties in regards to preoperative examinations. The time taken to perform the tests (median of 123 days) was found to be excessively long, and prevented the advantage provided by the high MELD score from benefiting patients with major liver dysfunctions. This problem can be attributed to public administration in healthcare, and it is not associated to the structure of liver graft allocation by MELD and its exception scores. The long waiting time favors patients without risk of imminent death from liver disease. In the United States, the incidence of cancer patients on the waiting list ranges from $3.8 \%$ to $19.6 \% .^{7}$ In the same study, the dropout rate was $11.5 \%$ for HCC patients and the death rate for non-HCC patients was $17.7 \%$. In our sample, $26.5 \%$ of patients benefited from the special score; $59 / 69$ (85.5\%) because of cancer; 54/59 (91.0\%) of them had HCC. In this group of patients there was no patient dropout for tumor growth beyond the Milan criteria. Mortality on the waiting list, among patients without special score, was $17.3 \%$. The public healthcare authority is also responsible by another problem - the low rate of organ procurement for transplantation in our country. When extreme, organ shortage also interferes in the allocation. The mathematical theory applied to liver transplant allocation shows that, below a certain organ procurement rate, improvements in the selection process lose their effectiveness, behaving as a random choice. $^{8}$

In Brazil and the United States, the organ procurement activity for transplantation, as well as the size of the waiting lists, are heterogeneous among different states. ${ }^{9}$ Thus, there are different combinations of high or low procurement rates or small or large waiting lists. Such variations influence cancer patient pre-transplant mortality or dropout rates. However, for patients with cancer, the assigned special score has a fixed value, regardless of the procurement rate and the queue size with their different MELD values. This policy relativizes the impact of special scores on waiting lists. In some, such as the one in the present study, the privilege granted to patients with cancer or other special situations seems exaggerated. In others, with many patients and high MELD, the score may be insufficient. Regional differences in the mean MELD score and its implication on the characteristic of transplants performed have been previously reported in the literature, after the implementation of this allocation model. ${ }^{10}$ In our study 
we discuss whether there is proportionality between the benefit brought about by the fixed special score, established in Brazil, and the risk faced by severely ill liver disease patients. This issue has been discussed in regards to transplant involving patients with hepatopulmonary syndrome in another country. ${ }^{11,12}$ Also in this case, the special score greatly favored patients with the syndrome, rather than transplant candidates with high scores for liver dysfunction. Regional differences in organ procurement rate and the length of the list of candidates for transplantation, make the problem relevant. ${ }^{5,11,13}$ In addition, the favoritism towards patients with HCC may be wrongly granted, being unfair to patients listed for liver dysfunction. The pathological study of explants showed that not all cases diagnosed based on imaging studies were worthy of a special score. $^{14}$

The authors propose the development of a special scoring model with values related to the median score of the patients who come to transplantation in each regional list. Thus, on lists full of critically ill patients with high scores, those patients with special scores receive higher marks. Otherwise, on lists with less severe cases, the score for cancer and other circumstances would also be less expressive. This proposal addresses regional differences on the waiting list, making the special score impact proportional to the MELD values of the patients who score only by liver disease. However, HCC biological behavior differences are not considered, as in the French model. ${ }^{15}$ In this model, patients with stage $\mathrm{T} 1$ tumors receive less important scores than their counterparts with stage T2 tumors. The score, which is progressive in nature, is still added to the calculated MELD score, which produces another differentiation for patients with more advanced liver disease. The result is obtained from the transplant after the time waited, 6 months on average to T2 and one year to T1.

The findings of this study are similar to those from some American studies. ${ }^{7,16}$ Despite the clear difference in the overall rate of organ procurement between the two countries; in both countries there are wide variations in the number of transplants by region. Notwithstanding, the special score for HCC protects and sometimes greatly benefits transplantation for this indication, even in regions with a lower organ procurement rate. A comprehensive review on the special score for HCC has been recently published, where the authors briefly reviewed the various organ allocation models based on MELD, with its scoring criteria for special situations. ${ }^{17}$
Despite the conclusion that the scoring model for special situations should be reviewed, a proposal is yet to be formulated.

Adapting HCC patients' scores could mean a longer waiting time on some lists. However, recent studies showed that HCC patients had better disease-free survival when the wait was a little longer, due to the selection effect provided by the observation period. ${ }^{18}$ The same does not happen with patients with parenchymal disease, who have mortality directly related to MELD. Moreover, thanks to the development of diagnostic imaging, patients with chronic liver diseases have their $\mathrm{HCC}$ detected increasingly early, and they may benefitted from a more aggressive treatment with curative intent or as a bridge in cases of longer waits; while patients with hepatic impairment due to cirrhosis depend entirely on transplantation as treatment. ${ }^{19}$ Early diagnosis is beneficial because tumor size is often associated with vascular invasion and to more aggressive phenotypes than the number of nodes. ${ }^{5}$

The main limitation of the study is the interpretation of an organ allocation system solely based on data from a single waiting list. However, its greatest benefit is that it shows the particularities of different lists and their inadequacy vis-à-vis a national system that has established and more general rules. Another limitation relates to the participants coming from a public teaching hospital. The difficulties encountered in the preparation of patients in the pre-transplant assessment and preoperative care may not be the same as in other samples from private hospitals.

\section{CONCLUSION}

We conclude that the current liver grafts allocation system disproportionately favors patients with special scores, especially those with hepatocellular carcinoma, to the detriment of patients with chronic liver disease, high MELD and high mortality risk. We propose to change the distribution system for a regionalized model, where the maximum score given to patients with special points such as hepatocellular carcinoma and others, is equal to the median MELD transplant patients in the last three months from the same geographical region. In such a model we expect an automatically updated balance between the score needed to allow special diseases to lead to transplant and the score obtained from calculated MELD of chronic cirrhotic patients without exception scores. 
Agnaldo Soares Lima, Nathália Nunes Godinho Lopes, Bárbara Buitrago Pereira, Leandro Ricardo Navarro Amado

\section{RESUMO}

A alocação de órgãos pelo MELD foi instituída em diversos países, com intuito de reduzir a mortalidade em lista de espera. Entretanto, nesse sistema, pacientes com neoplasia e algumas outras situações recebem pontuação especial. Objetivo: Verificar a equanimidade da distribuição de órgãos pelo sistema MELD entre diferentes grupos de doenças. Casuística e Método: Estudo retrospectivo envolvendo pacientes adultos entre 2009 e 2013 . Dados demográficos, indicação ao transplante e pontuação MELD foram confrontados com a incidência de transplante ou óbito com a procedência do paciente e grupos de doenças. Diferenças foram consideradas significativas quando $p<0,05$. Resultados: 260 pacientes selecionados tinham como evento final o transplante ou óbito pré-transplante. A mediana de idade foi de 54,9 anos (12,1 -73,9 anos), 70,4\% eram homens acometidos por doenças hepatocelulares crônicas em $63,3 \%$, especialmente cirrose etanólica $(33,1 \%)$ e cirrose pós-viral C $(24,2 \%)$. Pacientes com situação especial representaram $26,5 \%$ dos pacientes listados. Esses pacientes receberam $31 \%$ dos fígados transplantados e tiveram menor mortalidade pré-transplante ou dropout $(14,2$ vezes menor) que os demais pacientes $(p<0,001)$. Receber pontuação especial resultou em maior probabilidade de ser transplantado. Conclusão: Os autores propõem o uso de escore regionalmente variável para situações especiais, que deve ser baseado no escore mediano do MELD dos últimos transplantados por doença hepática crônica, para não prejudicar pacientes com acesso ao transplante pelo MELD calculado.

Descritores: Transplantação, Equidade na Alocação de Alocação de Recursos, Carcinoma Hepatocelular

\section{REFERENCES}

1. FJP - Fundação João Pinheiro. Regiões de Planejamento, 3rd. Belo Horizonte-MG, Brazil (S.N.): 1992.

2. Malinchoc M, Kamath PS, Gordon FD, Peine CJ, Rank J, ter Borg PC. A model to predict poor survival in patients undergoing transjugular intrahepatic portosystemic shunts. Hepatology 2000;31:864.

3. Gines P, Berl T, Bernardi M, Bichet DG, Hamon G, Jimenez $W$, et al. Hyponatremia in cirrhosis: from pathogenesis to treatment. Hepatology 1998;28:851

4. Kim WR, Biggins SW, Kremers WK, Wiesner RH, Kamath PS, Benson JT, et al. Hyponatremia and mortality among patients on the liver-transplant waiting list. N Engl J Med 2008;359:1018.

5. Pomfret EA, Washburn K, Wald C, Nalesnik MA, Douglas $D$, Russo M, et al. Report of a national conference on liver allocation in patients with hepatocellular carcinoma in the United States. Liver Transpl 2010;16:262.

6. Lima AS, Martins KPM, Almeida FC, Faria LC. [Migration of patients for liver transplantation]. Rev Med Minas Gerais 2011;21:413.

7. Washburn K, Edwards E, Harper A, Freeman R. Hepatocellular carcinoma patients are advantaged in the current liver transplant allocation system. Am J Transplant 2010;10:1643.
8. Oliveira AF, Ferreira RPM, Lima AS. Liver transplant waiting list simulation - An agent based model. ICAART 2011 Proceeding of the 3rd International Conference on Agents and Artificial Intelligence; Rome, Italy2011. p. 462.

9. Kadry Z, Schaefer EW, Uemura T, Shah AR, Schreibman I, Riley TR, 3rd. Impact of geographic disparity on liver allocation for hepatocellular cancer in the United States. J Hepatol 2012;56:618.

10. Schaffer RL, 3rd, Kulkarni S, Harper A, Millis JM, Cronin DC, 2nd. The sickest first? Disparities with model for endstage liver disease-based organ allocation: one region's experience. Liver Transpl 2003;9:1211.

11. Sulieman BM, Hunsicker LG, Katz DA, Voigt MD. OPTN policy regarding prioritization of patients with hepatopulmonary syndrome: does it provide equitable organ allocation? Am J Transplant 2008;8:954.

12. Goldberg DS, Krok K, Batra S, Trotter JF, Kawut SM, Fallon MB. Impact of the hepatopulmonary syndrome MELD exception policy on outcomes of patients after liver transplantation: an analysis of the UNOS database. Gastroenterology 2014;146:1256.

13. Burr AT, Shah SA. Disparities in organ allocation and access to liver transplantation in the USA. Expert Rev Gastroenterol Hepatol 2010;4:133. 
14. McCormack L, Gadano A, Lendoire J, Imventarza O, Andriani $\mathrm{O}$, Gil O, et al. Model for end-stage liver diseasebased allocation system for liver transplantation in Argentina: does it work outside the United States? HPB (Oxford) 2010;12:456.

15. Francoz C, Belghiti J, Castaing D, Chazouilleres O, DuclosVallee JC, Duvoux C, et al. Model for end-stage liver disease exceptions in the context of the French model for end-stage liver disease score-based liver allocation system. Liver Transpl 2011;17:1137.

16. Schuetz C, Dong N, Smoot E, Elias N, Schoenfeld DA, Markmann JF, et al. HCC patients suffer less from geographic differences in organ availability. Am J Transplant 2013;13:2989.
17. Toso C, Mazzaferro V, Bruix J, Freeman R, Mentha G, Majno $P$. Toward a better liver graft allocation that accounts for candidates with and without hepatocellular carcinoma. Am J Transplant 2014;14:2221.

18. Schlansky B, Chen Y, Scott DL, Austin D, Naugler WE. Waiting time predicts survival after liver transplantation for hepatocellular carcinoma: a cohort study using the United Network for Organ Sharing registry. Liver Transpl 2014;20:1045.

19. Neuberger J. Liver allocation for patients with hepatocellular carcinoma. Liver Transpl 2010;16:249. 